\title{
Sanidad Militar y aspectos sanitarios en Fernando Poo durante el gobierno de los brigadieres (1859-1869)
}

\author{
De Granda Orive J.*
}

Sanid. mil. 2011; 67 (1): 53-60; ISSN: 1887-8571

\begin{abstract}
RESUMEN
La aprobación en 1858 del primer estatuto orgánico de la colonia estableció una nueva organización administrativa y militar para las islas con la que se buscaba dar un impulso a la colonización de Guinea. Durante los diez años de vigencia de este decreto hubo al frente de la gobernación de estas posesiones cuatro Brigadieres de Ejército y fue una sección del Cuerpo de Sanidad Militar la encargada de la asistencia sanitaria de la población. Se estudia en este trabajo su creación y actividad así como las condiciones ambientales y sanitarias que influyeron en su trabajo.
\end{abstract}

PALABRAS CLAVE: España, Guinea, Fernando Poo, Sanidad Militar, Siglo XIX.

\section{The Medical Service and medical aspects in Fernando Poo during the government of the brigadiers (1859-1869)} SUMMARY

The first organic statutes of the colony passed in 1858, established a new administrative and military organization for the islands which tried to push forward the colonization of Guinea. During the ten years of applicability of this decree the governors of these possessions were four Army brigadiers, while a Medical Service platoon was responsible for the medical care of the population. In this article its creation and activities are studied as well as the environmental and sanitary conditions that had an impact on its work.

KEY WORDS: Spain, Guinea, Fernando Poo, Medical Service, 19th century.

\section{INTRODUCCIÓN}

En 1777 España y Portugal firman el Tratado Preliminar de límites de San Ildefonso ampliado en 1778 por el Tratado de El Pardo por el cual Portugal cedía a España las islas de Fernando Poo y Annobon y la parte del litoral del continente comprendida entre el cabo Formoso y el cabo López. Fernando Poo es una isla volcánica situada en el golfo de Guinea a $32 \mathrm{~km}$. de las costas de Camerún y una superficie de $2.017 \mathrm{Km}^{2}$, estando habitada por bubis, etnia autóctona de la isla con origen en migraciones anteriores al siglo XV procedentes del continente. Annobon es una isla más pequeña $\left(17 \mathrm{Km}^{2}\right)$ situada en el hemisferio austral, frente a las costas de Gabón.

Para tomar posesión de estas tierras, en abril de 1778, partió de Montevideo una expedición al mando del Conde de Argelejo llevando como segundo al teniente coronel de Artillería Joaquín Primo de Rivera. Tras diversas vicisitudes y calamidades, incluyendo la muerte del Conde de Argelejo y el amotinamiento de la tropa, la expedición retorna a Montevideo en 1781 sin prácticamente cumplir sus objetivos. Siguió después un periodo de olvido de las islas fomentado, sin duda, por su fama de insalubridad, periodo que fue aprovechado por Gran Bretaña para establecerse en ellas y fundar, con el nombre de Port Clarence, la población que posteriormente sería Santa Isabel.

\footnotetext{
${ }^{*}$ Licenciado en Derecho.

Dirección para correspondencia: grandaorive@gmail.com
}

Recibido: 27 de enero de 2010

Aceptado: 13 de septiembre de 2010
La soberanía de España sobre las islas se impone en 1843 gracias a la expedición mandada por el capitán de navío Juan José de Lerena que logró, además, la anexión de Corisco como consecuencia del acatamiento de su rey, Bonkoro, de la soberanía española. Dos años más tarde, una nueva expedición al mando del capitán de fragata Nicolás Manterola ratifica la soberanía de España sobre las islas y firma un nuevo tratado, en su visita a Corisco, con su rey en el que se menciona a Elobey como parte integrante de su reino ${ }^{1}$.

\section{EL GOBIERNO DE CARLOS CHACÓN}

En 1858 para ejercer nuestro dominio definitivo sobre las islas de Fernando Poo, Annobon, Corisco y sus dependencias, se organiza una expedición, la más numerosa hasta entonces, comandada por el capitán de fragata Carlos Chacón y Michelena, comandante del vapor «Vasco Núñez de Balboa» y primer Gobernador efectivo de la colonia ${ }^{2}$.

El 19 de abril de 1858 partía de Cádiz el vapor seguido, días después, por el bergantín «Gravina», la goleta «Cartagenera» y la urca «Santa María» con víveres, pertrechos, medicamentos para seis meses y los materiales necesarios para la construcción de un hospital de madera con capacidad para cuarenta enfermos. Como jefe de sanidad de la expedición se encontraba el primer médico de la Armada José Pérez Lora que durante el tiempo que estuvo

\footnotetext{
${ }^{1}$ La pequeña isla de Corisco $\left(15 \mathrm{~km}^{2}\right)$ y las dos de Elobey: Elobey grande y Elobey chico (total 2,46 $\mathrm{Km}^{2}$ ) están situadas en el estuario del río Muni.

${ }^{2}$ Carlos Chacón fue nombrado gobernador de Guinea por real orden de 30 de marzo de 1858.
} 


\section{J. De Granda Orive}

en Guinea llevó a cabo las primeras investigaciones sobre enfermedades endémicas del trópico ${ }^{3}$.

El 22 de mayo llegó a la bahía de Santa Isabel el «Vasco Núñez de Balboa» seguido los días 10, 12 y 15 de junio, respectivamente, por la «Cartagenera», el «Gravina» y la «Santa María». La ciudad de Santa Isabel que recibió a los expedicionarios españoles no era más que un pequeño poblado con casas de madera, a excepción de la residencia del cónsul británico que era de hierro corrugado traído expresamente de Inglaterra; siendo la mayor parte de planta baja y techos de tejamanil o de bambú. Las casas de los colonos más opulentos, casi todos comerciantes ingleses, estaban elevadas sobre el terreno y situadas sobre la plataforma que se asoma a la bahía, antiguo cráter de un volcán sumergido que, a su vez, se encuentra delimitada por dos lenguas de tierra: Punta Fernanda, al este, y Punta Cristina, al oeste ${ }^{4}$. La población de Santa Isabel era mayoritariamente de raza negra y masculina. Según el censo de 1858 la población total era de 858 personas (578 hombres y 280 mujeres) siendo de raza blanca 13 personas: 7 británicos y 6 jesuitas españoles. La población negra tenía un carácter heterogéneo: fernandinos, krumanes y gente de la costa. Los fernandinos eran descendientes de negros libertos establecidos en la isla, con formas culturales británicas y que se dedicaban básicamente al comercio del aceite de palma. Eran la alta sociedad africana de la isla. Los krumanes eran trabajadores, generalmente contratados por campañas de dos años, originarios de la costa del Kru. Con el tiempo este término se generalizó para hacer referencia a braceros procedentes de Liberia, Sierra Leona y Costa de Marfil. Con el término gente de la costa se designaba a los inmigrantes originarios de diversos puntos del África Occidental que eran utilizados generalmente como mano de obra ${ }^{5}$. En el aspecto sanitario, el abandono era absoluto, siendo ejercida las funciones de médico, únicamente y de manera abusiva («lleva cinco duros por visita»), por el cónsul británico y médico, $\mathrm{Mr}$. Hutchinson $^{6}$.

De inmediato comenzaron los trabajos de desmonte en Punta Fernanda para la construcción del futuro hospital. En una comunicación de 26 de octubre de 1858 (Gaceta de 14 de diciembre de 1858) el gobernador Chacón informa al Ministerio de Guerra y Ultramar que las obras del hospital avanzaban a buen ritmo, hallándose casi terminadas la tablazón y techumbre y que en breve comenzaría la construcción de las dependencias indispensables. Comunicaba, asimismo, que el estado sanitario de la colonia era regular ${ }^{7}$. Las obras del nuevo hospital terminaron en diciembre de 1858 y el día 19 se inauguró el establecimiento en un acto solemne con misa cantada y Tedeum. Acudieron a la

\footnotetext{
${ }^{3}$ Joaquín J. Navarro en su libro Apuntes sobre el estado de la costa occidental de África y principalmente de las posesiones en el golfo de Guinea. Imprenta Nacional, Madrid, 1859, pp. 47-48, menciona a este médico y dice «....está haciendo interesantes investigaciones acerca de las enfermedades del país, y atiende con incansable celo y caridad a los enfermos de los buques, y aun a los del país, a estos últimos sin retribución alguna».

${ }^{4}$ NAVARRO, Joaquín J.: op.cit., pp. 69-75.

${ }^{5}$ Ver CASTRO ANTOLÍN, Mariano L. de: La población de Santa Isabel en la segunda mitad del siglo XIX. Asociación Española de Africanistas A.E.A., Madrid, 1996, cuaderno monográfico 1.

${ }^{6}$ Correspondencia particular publicada en la Gaceta de 28 de agosto de 1858.

${ }^{7}$ A finales de julio fue necesario habilitar la urca «Santa María» como hospital provisional preparando su sollado para acomodar 18 camas.
}

inauguración los oficiales, marinería y tropa de los buques españoles surtos en la bahía, el cónsul británico y los oficiales, de la misma nacionalidad, de los buques encargados de la exploración del río Níger que en esa fecha se encontraban en el puerto de Santa Isabel.

La inauguración del hospital no supuso la terminación de las obras pues en enero de 1859 continuaban los trabajos de desmonte y nivelación del terreno inmediato al edificio.

El 13 de febrero de 1859, mediante real orden, la reina Isabel II aprobaba con satisfacción la construcción del hospital, autorizaba al Gobernador la admisión de marineros extranjeros en el hospital y le daba libertad para fijar la cantidad que habrían de abonar en concepto de gastos de hospitalización.

\section{EL PRIMER ESTATUTO ORGÁNICO DE LA COLONIA Y LA SANIDAD MILITAR}

En España, mientras tanto, se ve la necesidad de impulsar la colonización de nuestras posesiones en el golfo de Guinea y, para ello, el 13 de diciembre de 1858 (Gaceta de 15 de diciembre) se dicta un real decreto, rubricado por O'Donnell, que establece una nueva organización política, administrativa y militar de la colonia. El desarrollo colonial requería una decidida actuación y protección de la empresa por parte del Estado, la colaboración de comerciantes y colonos españoles y la existencia de una red fluida de comunicaciones entre Guinea y la metrópoli. Al mismo tiempo se fijaron cuatro objetivos en el afán colonizador: españolización de Fernando Poo haciendo olvidar su pasado inglés, atracción de los bubis, estabilidad legal y administrativa y el desarrollo comercial mediante la conversión de Santa Isabel en el principal depósito comercial y puerto de cabotaje de todo el golfo de Guinea ${ }^{8}$. Se abre así un periodo en que al frente de la gobernación de estos territorios van a estar Brigadieres de Ejército. En los diez años de vigencia de este primer estatuto orgánico se sucedieron en el gobierno de las islas cuatro brigadieres de ejército: José de la Gándara y Navarro (1858-1862), Pantaleón López de la Torre Ayllón (1862-1865), José Gómez de Barreda (1865-1868) y Joaquín de Souza y Gallardo (1868-1869).

El real decreto de 13 de diciembre de 1858 establece en su artículo 3 que se destinarán a las referidas posesiones las fuerzas militares que el Ministerio de la Guerra estime necesarias y añade que «para las necesidades de estas fuerzas y para las de aquella población en general se enviarán a las posesiones del golfo de Guinea el número de individuos del Cuerpo de Sanidad Militar que por el ministerio de la guerra se crea necesario».

La acogida prestada a este artículo por parte del Cuerpo de Sanidad Militar y, sobre todo, entre los Segundos Ayudantes médicos, fue importante, presentándose numerosos voluntarios para formar parte de la expedición ${ }^{9}$. Sorprendentemente, entre los médicos de entrada no hubo ninguna solicitud.

Dos son las consecuencias del artículo 3 del real decreto: primera, la real orden de 15 de diciembre de 1858 (Gaceta de 3 de enero de 1859) por la que se crea una compañía de infantería con

${ }^{8}$ CASTRO, Mariano de y NDONGO, Donato: España en Guinea. Construcción del desencuentro: 1778-1968. Ediciones Sequitur, 1998, pp. 59-63.

${ }^{9}$ Diario «La Época» de 31 de diciembre de 1858. 
destino a Fernando Poo y segunda, la real orden de 14 de enero de 1859 expedida por el Ministerio de Guerra y relativa al Cuerpo de Sanidad Militar de Fernando Poo.

La compañía de infantería de Fernando Poo se organizó e instruyó en Aranjuez entre los meses de enero y abril de 1859 y entre sus oficiales se encontraba un Segundo Ayudante médico que contaba con un botiquín del modelo aprobado por real orden de 4 de noviembre de 1858 .

La real orden de 14 de enero de 1859 establecía, por su parte, que la sección del Cuerpo de Sanidad Militar en Fernando Poo constaría, por ahora, de dos Primeros Ayudantes médicos, un Primer Ayudante farmacéutico y dos practicantes, uno de medicina y otro de farmacia. El artículo 2 de la orden añadía que «las referidas plazas de primeros ayudantes se cubrirían al ascenso en los aspirantes de la clase inmediata inferior de la escala de la península y estos ascensos serán válidos en dicha escala a los tres años de permanencia en las expresadas islas o demás adyacentes de dominio español». Finalizaba la norma disponiendo que se debía remitir a Fernando Poo una colección de instrumentos de cirugía y de autopsia de los existentes en el hospital militar de Madrid, así como también un repuesto de medicamentos y medios de curación.

Esta real orden se completó con otra de 5 de marzo de 1859 que disponía que los primeros ayudantes médicos y farmacéuticos destinados en Fernando Poo gozarían la antigüedad de sus nuevos empleos desde el día que se produjera el embarque hacia la isla. Unos años después, en virtud de una instancia presentada por el segundo ayudante farmacéutico Cleto Andéchaga solicitando la derogación de esta norma, se dictó una real orden de 26 de julio de 1865 disponiendo que en lo sucesivo los oficiales que fuesen destinados a Fernando Poo obtendrían el empleo inmediato ocupando siempre en la escala el puesto que les correspondiera y cuando regresaren a la península sólo tendrían derecho a conservar el empleo como personal, si habían permanecido en la colonia tres o más años.

El 29 de enero de 1859 se nombra, como primeros ayudantes médicos, con destino en Fernando Poo a los segundos ayudantes José Carbonell y Xammar y Marcelino Pérez Llanos y como primer ayudante farmacéutico al segundo Donato Sáenz Domínguez. Asimismo se nombra como practicante de medicina a Saturnino Pérez Díaz y como practicante de farmacia a Antonio González Serrano.

Por último, en marzo de 1859 (Gaceta de 28 de marzo) el Ministro de Guerra comunica al Director General de Sanidad Militar que la Reina autorizaba que la botica militar de las islas de Fernando Poo y Annobon pudiera expender a los colonos y habitantes de las islas todas las medicinas que necesitaren, con arreglo a las tarifas de precios aplicables a los presidios menores de África.

\section{EL GOBIERNO DE LOS BRIGADIERES}

El brigadier José de la Gándara ${ }^{10}$ llegó a Santa Isabel a bordo de la corbeta «Ferrolana» el día 27 de agosto de 1859 y tomó posesión de su cargo, relevando a Carlos Chacón, el 1 de septiembre. Acompañaban al nuevo Gobernador en la expedición

\footnotetext{
${ }_{10}$ Fue nombrado Gobernador el 16 de diciembre de 1858
}

compuesta por la citada corbeta y la urca «Santa María» además del elemento militar, constituido por oficiales de Ingenieros, de Artillería, de Sanidad y de la compañía de infantería, empleados civiles del gobierno, cuatro misioneros de la compañía de Jesús y ciento veintiún colonos, todos ellos optimistas ante su nuevo futuro.

No obstante, pronto, las duras condiciones ambientales y sobre todo, las enfermedades endémicas del territorio se van a imponer sobre los mejores deseos de los expedicionarios.

En los últimos meses de 1859 las «calenturas perniciosas»y la disentería obligaban, al no ser suficientes las camas del hospital militar, a establecer una enfermería provisional para los colonos a bordo de la urca «Santa María» y al suministro gratuito, por orden del Gobernador, de sulfato de quinina como medida terapéutica. Se ordenó también que los medicamentos solicitados por los colonos fueran suministrados por su precio de coste. Algunos de los colonos enfermos, ante las duras condiciones de vida, solicitaron su repatriación, solicitudes que fueron, en principio, denegadas, pues significaban el fracaso de los planes de colonización concebidos para Guinea. Sin embargo, el paso del tiempo y el aumento de los enfermos obligaron, finalmente, a su aceptación por el Gobernador ${ }^{11}$.

La compañía de infantería de Fernando Poo se encontraba en una situación similar. Desde su llegada a la isla y en tanto no estuviera concluida la construcción de la casa-cuartel, la compañía quedó alojada en la corbeta «Ferrolana» pasando, en abril de 1860 , a la fragata «Isabel II» que quedó convertida en pontón y utilizándose como cuartel y hospital flotante y, en definitiva, como un medio, según la creencia de entonces, para preservar a la tropa del paludismo. A pesar de estas medidas la situación sanitaria de la compañía era desastrosa. Por ello, el 27 de junio de 1860 se dictó una real orden en donde se establecían dos puntos. Primero, que se hiciera extensiva a Fernando Poo la real orden de 18 de octubre de 1855 dictada para Cuba y Puerto Rico en virtud de la cual quedaba autorizado el regreso a la península de los individuos de la clase de tropa en quienes se presentase la tisis, ampliando esta autorización a cualquier otra enfermedad de las más especialmente graves en el golfo de Guinea y segundo, que respecto de los individuos que se inutilizasen para el servicio fueran igualmente enviados a la península y se les expidiera la licencia absoluta cuando llegasen, después de un nuevo reconocimiento médico.

El primer ayudante médico Pérez Llanos en una carta de octubre de 1860 dirigida a La España Médica ${ }^{12}$ hace referencia a la salida para la península en el vapor «Marqués de la Victoria», gravemente enfermos, de siete colonos, un comandante a las órdenes del Gobernador, un sargento primero y ocho soldados de la compañía de infantería. Refiere también que en junio cesó la disentería y añade que se encuentra solo pues su compañero, el primer ayudante Carbonell, está enfermo desde que llegó ${ }^{13}$. Car-

\footnotetext{
${ }^{11}$ Entre los colonos fallecidos en Guinea y los que regresaron, vencidos, a España, a finales de 1860 sólo quedaban en Fernando Poo tres colonos y en 1874 uno.

12 «La España Médica» de 15 de noviembre de 1860

${ }^{13}$ El médico Marcelino Pérez Llanos murió en Santa Isabel a principios de 1861 aquejado de fiebres palúdicas. Por real orden de mayo de 1861 fue nombrado médico con destino a Fernando Poo el primer ayudante José de Villar Rubín y Yebra.
} 


\section{J. De Granda Orive}

bonell, al que se le concedió el pase a la península, fue sustituido por el segundo ayudante médico Fernando Piquer nombrado en noviembre de $1860^{14}$.

A estas calamidades hay que sumar otra no menos importante: la escasez pertinaz de alimentos que sufrió Fernando Poo durante el gobierno de los Brigadieres y, principalmente, durante los primeros años de la colonia. Distintas cartas remitidas a los diarios españoles por expedicionarios reflejan esta situación de carestía: «galleta podrida y unas habichuelas muy duras es lo único que comemos» ${ }^{15}$, «en lo que más sufrimos es en la carencia grande que tenemos algunas veces de comestibles, habiendo pasado cerca de un mes sin tener pan, y comiendo galleta: la carne de vaca y de carnero, mejor dicho, la carne en general, es un objeto de puro lujo» ${ }^{16}$. Otra carta de marzo de $1861{ }^{17}$ refiere la carestía de harina que tiene la colonia y añade que el Gobernador y el Administrador han cedido al hospital militar sus raciones, sujetándose como el resto de la población a comer galleta hasta la llegada del siguiente vapor procedente de España.

En enero de 1861 llega a la bahía de Santa Isabel la fragata «Perla» y por consejo de los médicos del hospital y de la armada se embarca a la tropa de la compañía de infantería, invadida por las fiebres, para ver si un periplo por las islas mejoraba su salud. Fueron 42 días de navegación en los que visitaron las islas de Corisco, Elobey y Annobon. Según informe del médico de la armada Diego Latorre, poco o nada se consiguió con esta medida. La fragata «Perla» fue convertida posteriormente en pontón y sirvió para alojar un grupo de confinados ${ }^{18}$ llegados a finales de 1861.

En 1862 se presentó la primera de las tres grandes epidemias que afectaron Fernando Poo en este periodo. Se trataba de fiebre amarilla, importada de la costa africana por un pontón inglés que recaló en Santa Isabel, y que causó numerosas víctimas. Entre la dotación de los buques de la Armada hubo 41 fallecidos ${ }^{19}$ afectando también a los confinados de Loja que, como medida humanitaria, fueron realojados en un barracón cercano a Basilé, en la ladera del pico Santa Isabel.

Este episodio trajo consigo una nueva responsabilidad de los médicos militares. E1 26 de noviembre de 1862 se dictó una real orden por la cual los facultativos castrenses debían visitar los buques que hubiera en la colonia y redactar un informe para, posteriormente, por parte del Gobernador, emitir una certificación de sanidad a los que se dirigieren a España. Después, en 1863, se facultó al Gobernador a adoptar las medidas oportunas cuando se hubiera declarado una epidemia en la costa de África.

En noviembre de 1863 el grueso de la fuerza peninsular de la compañía de infantería compuesta de convalecientes y aquejados de fiebres (cuarenta hombres), acompañados por el primer ayudante José de Villar, abandonaron Santa Isabel para instalarse en la recién construida casa-cuartel de la localidad de Basilé, a nue-

\footnotetext{
${ }^{14}$ Fernando Piquer regresó enfermo a España en 1862.

${ }^{15}$ Diario «La Iberia» de 10 de mayo de 1860.

${ }^{16}$ Diario «La Esperanza» de 11 de octubre de 1861.

17 Diario «La España» de 17 de abril de 1861.

${ }^{18}$ Los confinados fueron enviados a Fernando Poo por el Gobernador de Málaga al ser responsables de la sublevación de Loja. Fueron puestos en libertad a finales de 1862 .

${ }^{19}$ IGLESIAS Y PARDO, Luis: Observaciones teórico-prácticas sobre las fiebres africanas de Fernando Poo. Imprenta y Lit. de Taxonera, Ferrol, 1874, p. 12.
}

ve kilómetros de la capital y a 470 metros sobre el nivel del mar. Esta casa-cuartel, llamada Santa Cecilia, era una casa de reposo, convalecencia y recuperación del personal europeo de la colonia y junto a la enfermería (antiguo barracón en que se alojaron los confinados de Loja), las caballerizas y las chozas de los krumanes formaba un pequeño poblado. El gobernador López Ayllón, en un informe al Ministerio de Ultramar de fecha 20 de abril de 1864 dice que durante los cinco meses que estuvo acantonada la tropa en Santa Cecilia, no hubo baja alguna y que los convalecientes se recuperaron completamente. El primer ayudante médico Villar publicó, asimismo, un informe médico ${ }^{20}$ por encargo del Gobernador y en él finaliza diciendo que tanto la tropa como los oficiales y empleados civiles que han residido en la montaña se han repuesto y reconquistado su salud y añade que la creación de este establecimiento es una «ventaja de salubridad».

El 28 de febrero de 1864 desembarcan en Santa Isabel, procedentes de cabo Palmas, un grupo de trabajadores krumanes. El 6 de marzo se presenta en uno de ellos el primer caso de una epidemia de viruela que afectó, principalmente, a la población negra de la colonia. Según se pudo conocer con posterioridad, la enfermedad comenzó en el buque inglés «Armenian» que hacía la ruta de Liverpool hasta la costa africana siendo ulteriormente importada a Fernando Poo por el vapor, también inglés, «Retriever» al llevar carga y pasaje a Santa Isabel. En 1864 se encontraban destinados en la isla el médico mayor Melitino López SánchezNieto, los primeros ayudantes médicos Antonio Serrano Borrego y José de Villar (cesó en julio de 1864) y el primer ayudante farmacéutico Ignacio Vives Noguer, que había sustituido al de su misma clase Antonio María Quer Vallcendrera. Los médicos militares españoles, ante el aumento de los enfermos, llevaron a cabo reiteradas tentativas de vacunación; primero, con algunos cristales de vacuna encontrados en la farmacia del hospital y después, con linfa procedente de la sociedad jenneriana de Londres con resultados infructuosos en ambos casos. Los propios indígenas, motu proprio, sin consulta ni consejo facultativo, optaron, en dos periodos distintos de la epidemia, por la inoculación de la viruela tomando el pus de sujetos en que se había desarrollado de manera benigna. Los primeros pacientes fueron llevados a una casita situada en el bosque, al otro lado del río Cónsul, río que discurre próximo a Santa Isabel hasta su desembocadura en el mar. La virulencia de la enfermedad obligó a la construcción, por orden del Gobernador, de un barracón de bambú en un sitio próximo al alojamiento de los krumanes y emancipados cubanos llegados en agosto de 1862, para dar asistencia a éstos y al resto de la población negra. En enero de 1865 se dio por extinguida la epidemia que aquejó, dentro de la población negra, a más de seiscientas personas, con el desenlace de noventa y siete muertos y respetando a la población blanca, con la única excepción del maestre de víveres del pontón «Isabel II», al que la viruela afectó de manera benigna ${ }^{21}$.

\footnotetext{
${ }^{20}$ VILLAR, José de: «Informe médico acerca del establecimiento de Santa Cecilia en Fernando Poo» en Revista de Sanidad Militar y general de ciencias médicas, 62, 1866, pp.444-448 y 63, 1866, pp. 462-467.

${ }^{21}$ LÓPEZ SÁNCHEZ-NIETO, Melitino: «Epidemia de viruelas sufrida en Fernando Poo en 1864» en Revista de Sanidad Militar Española y Extranjera 39, 40, 41, 42, 43, 45, 46, y 48, 1865 y en Revista de Sanidad Militar y general de ciencias médicas, 52 y 54, 1866 .
} 
A finales de 1864, ante el deterioro que sufría el instrumental médico y quirúrgico del hospital por efecto del clima, se remitió a Fernando Poo una nueva colección de instrumentos de cirugía.

En abril y septiembre de 1866 cesan, respectivamente, el primer ayudante Antonio Serrano y el médico mayor Melitino López. En Fernando Poo se encontraba, desde su nombramiento a finales de 1864, el primer ayudante médico Luis Fernández Maló y el primer ayudante farmacéutico Francisco Barbudo Cuevas (nombramiento de abril de 1865). Por real orden de julio de 1866 se destina a la colonia al primer ayudante Eduardo Baselga Chaves que, no obstante, permuta su destino en octubre con el de la misma categoría José Dubrull Maron. Los últimos nombramientos del Cuerpo de Sanidad Militar en la colonia corresponden al primer ayudante Carlos Rico Olivares que, ascendido en 1869 a Médico Mayor, será el último jefe de Sanidad Militar en Fernando Poo y al segundo ayudante médico Leopoldo Castro Blanc ${ }^{22}$.

En 1867 una nueva epidemia de fiebre amarilla, que según Luis Iglesias y $\operatorname{Pardo}^{23}$ no se quiso declarar y que figura en los estados sanitarios con el nombre de fiebre biliosa y perniciosa, afectó a la colonia desde el mes de octubre. Sugiere este médico de la Armada que la importación de la epidemia se debió al vapor «General Álava» que llegó a Santa Isabel el 24 de septiembre y partió rumbo a España el 9 de octubre. Añade que entre los días 18 y 30 de octubre diez individuos del pontón «Perla» fallecieron, continuando la mortandad en el mes siguiente, lo que llevó al abandono del pontón al ser considerado como el foco de infección. Fue sustituido, para esta misma utilidad, por el bergantín «Alcedo» llegado a Fernando Poo en diciembre de 1867 al mando del comandante Antonio Malludo. Luis Iglesias continúa diciendo en su libro que en 1868 la epidemia persistía y que fueron numerosos los fallecidos entre los que hay que destacar, en el mes de abril, al médico del pontón «Alcedo» Emilio Álvarez.

Mariano L. de Castro ${ }^{24}$, por su parte, nos dice que se trataba de una epidemia de tifus que en 1868 se propagó entre la población blanca de la colonia y que, tan crítica fue la situación, que hubo de abandonarse, por falta de personal, el pontón «Perla» quedando, tanto el pontón «Alcedo» como la goleta «Consuelo» muy mermados en su dotación. Añade que de la compañía de infantería de Fernando Poo, sólo en el mes de mayo, habían fallecido doce soldados por esta enfermedad.

Si nos ceñimos a los informes emitidos por la jefatura de Sanidad Militar de Fernando Poo los últimos meses de 1867 y primeros de 1868, nos fijamos en que las entradas y defunciones en el hospital los meses de noviembre y diciembre de 1867 son escasas ( 3 entradas y 1 muerto en noviembre y 8 entradas y 2 muertos en diciembre), mientras que en los siguientes meses de 1868 la situación cambia. Entre los meses de enero y julio de 1868 fueron hospitalizados 419 personas, habiendo fallecido en este periodo 42 individuos. Lo que no queda claro es el motivo de las muertes:

\footnotetext{
${ }^{22}$ Francisco Javier Balmaseda, confinado político cubano en la colonia, en su libro Los confinados a Fernando Poo e impresiones de un viage a Guinea. Imprenta de la Revolución, Nueva York, 1869, p. 251, tacha de inhumano y procaz a Leopoldo Castro con motivo del regreso de éste a la península en el vapor «San Antonio», en agosto de 1869, coincidiendo con el retorno de 180 confinados cubanos.

${ }^{23}$ IGLESIAS Y PARDO, Luis: op.cit., pp. 14-15.

${ }^{24}$ CASTRO ANTOLÍN, Mariano L.: op.cit., p. 10
}

el informe del primer trimestre de 1868, único que refleja las causas de defunción, establece la muerte de 10 personas por calenturas gastro-biliosas, de 6 personas por calenturas tifoideas y de 3 individuos por calenturas malignas. Los informes de los meses siguientes no indican las causas de las muertes.

El año 1869 comenzó en Guinea prácticamente sin novedad en materia sanitaria. El informe del primer trimestre de la jefatura de Sanidad Militar registra la entrada de 35 personas en el hospital (27 de tropa, 1 de la Armada, 6 entre los deportados de Cuba y 1 extranjero) siendo solamente 2 los muertos. Recoge además el informe que el estado en que se hallan las camas, los utensilios y los medicamentos es bueno.

En España la situación es distinta. Los acontecimientos revolucionarios que han dado lugar al destierro de la reina Isabel II y a la formación de un gobierno provisional a finales de 1868 , con la asunción de principios liberales, van a traer consigo, no sólo un cambio de sistema político, sino también, un cambio de mentalidad en el Ministerio de Ultramar. Se quiere variar el sistema político y administrativo vigente en el golfo de Guinea y lograr un ahorro en los gastos que la colonia ocasiona al Erario y, concretamente, al presupuesto de la isla de Cuba, del cual depende.

Para lograr estos objetivos se publica, por decreto de 12 de noviembre de 1868 (Gaceta de 13 de noviembre) el segundo estatuto orgánico de la colonia que, no obstante, no sería de aplicación hasta el ejercicio de 1869 para posibilitar así que las reformas fuesen convenientemente preparadas en su ejecución práctica mediante la publicación de los oportunos reglamentos.

La reducción de gastos se hace patente, entre otras medidas, en la unificación del cargo de Gobernador y de jefe de la Estación Naval en una misma persona con graduación, por lo menos, de Capitán de Fragata; en la supresión de la compañía de infantería de Fernando Poo; en la supresión de la sección de Sanidad Militar y en la creación de un consejo de gobierno compuesto por cinco personas (un Jefe de Fomento, el oficial con mayor graduación de la Estación Naval, un Juez asesor, un Secretario y un cura párroco) bajo la presidencia del Gobernador. Cada una de estas personas asumía numerosas competencias, correspondiendo la sanidad al Jefe de Fomento auxiliado por un servicio sanitario civil (artículo 13) compuesto por un médico-cirujano, dos practicantes de medicina y cirugía, un farmacéutico y un practicante de farmacia ${ }^{25}$. La provisión de estas plazas se verificaría por concurso o por libre nombramiento del Ministerio de Ultramar, del cual dependían.

El decreto de 1868 supuso, por tanto, el cese en sus destinos, a partir de julio de 1869 , de los oficiales y practicantes de Sanidad Militar destinados en Fernando Poo y su sustitución, en un primer momento, por los médicos de Sanidad de la Armada que formaban parte de la dotación de los buques de la Estación Naval y, posteriormente, por el personal civil contratado junto con los médicos de la Marina. Un anuncio oficial de 12 de abril de 1870, publicado en la Gaceta de 13 de abril, hace saber a José Gabarrón (médicocirujano) y a Francisco San Joaquín y Juan Culla (practicantes de medicina) que antes del día 23 tienen que presentarse en Cádiz para embarcar en el vapor «Ferrol» con destino a Fernando Poo.

\footnotetext{
${ }^{25}$ Para tener más información de este periodo ver CASTRO ANTOLÍN, Mariano L. de: «La revolución de 1868 y la Guinea Española» en Cuadernos de Historia Contemporánea, número extraordinario, 2003.
} 


\section{J. De Granda Orive}

\section{CONSIDERACIONES FINALES}

La información sobre el estado sanitario de las posesiones españolas en Guinea era escasa y fragmentaria: los informes remitidos a la península por los Gobernadores sobre la situación de la colonia regularmente terminaban con la frase «... siendo el estado sanitario satisfactorio». Solo de manera ocasional, y coincidiendo con las tres graves epidemias que asolaron Fernando Poo en la década estudiada, los informes reflejaron, de forma vaga e imprecisa, esta situación. No es hasta el gobierno de Barreda (1965) en que en la Gaceta comienzan a aparecer partes mensuales de las existencias, movimiento y necrología de enfermos atendidos en el hospital militar de Santa Isabel emitidos, todos ellos, por la Jefatura de Sanidad Militar de Fernando Poo. Los informes mensuales dividían el movimiento de enfermos en medicina y en cirugía añadiendo, ocasionalmente, otras categorías como venéreas, sarna y afecciones oftálmicas, indicando los pacientes entrados y salidos, los muertos y las existencias anteriores y finales. Los informes trimestrales eran más completos, reseñando, dentro de las categorías de medicina y cirugía, los movimientos y muertes de pacientes en función de las distintas enfermedades y determinando su procedencia. Añadían, además, unas observaciones médicas, meteorológicas, climáticas y económicas.

Del examen de los informes trimestrales, extrapolables, según mi opinión, a los años anteriores, podemos extraer no solo las enfermedades y dolencias más comunes padecidas en la colonia en este periodo, sino también, determinar los principales beneficiarios de la asistencia sanitaria militar. El mayor número de ingresos hospitalarios en estos años se debió a las denominadas fiebres intermitentes simples seguidas de las calenturas gastrobiliosas. Otras dolencias que requirieron el ingreso en el hospital, aunque en menor proporción, fueron: disentería, calenturas tifoideas, fiebres intermitentes malignas, afecciones de los órganos respiratorios, afecciones reumáticas y afecciones gastro-intestinales. Dentro de la categoría de cirugía las entradas hospitalarias se debieron principalmente a úlceras, afecciones venéreas, heridas y tumores. Las estadísticas elaboradas por los médicos de la Estación Naval correspondientes a los años 1868 y 1869 recogen datos similares ${ }^{26}$.

Se puede concluir, por tanto, que la isla de Fernando Poo, y más concretamente su parte baja y su franja litoral, eran eminentemente palúdicas y que el paludismo fue la principal causa de ingreso hospitalario y de defunción entre la población de Santa Isabel.

Con respecto a la procedencia de los pacientes, la asistencia hospitalaria estaba abierta a la población de Santa Isabel y a los marineros extranjeros con arreglo a unas tarifas. Ahora bien, no debemos olvidar que en Guinea, al igual que en otros contextos coloniales africanos, el dispositivo sanitario se orientó, inicialmente y de manera preferente, a los miembros del Ejército y a sectores de población necesarios para el mantenimiento de los intereses coloniales ${ }^{27}$. En este sentido, el sector de población de Fernando Poo más beneficiado de la asistencia hospitalaria fue-

\footnotetext{
${ }^{26}$ IGLESIAS Y PARDO, Luis: op.cit., pp.65-66.

${ }^{27}$ MEDINA DOMENECH, Rosa María: «Paludismo, explotación y racismo en Guinea Ecuatorial (1900-1939)» en http://www.asodegue.org/hcp0039. htm
}

ron los miembros del Ejército y de la Armada. Reflejo de esta realidad es el desahogo aparecido en una carta fechada en Fernando Poo el 28 de septiembre de 1863 y publicada en el diario «La Esperanza» de 20 de noviembre: «... hospitales, solo hay uno de madera, que está medio ruinoso y es puramente militar e inaccesible a los paisanos; boticas, una, poco surtida y también militar, porque aquí TODO ES MILITAR». En cuanto a los sectores de población necesarios para el mantenimiento de los intereses coloniales, básicamente trabajadores krumanes y emancipados cubanos, la asistencia sanitaria también estaba regulada. Los krumanes percibían un salario de 4 pesos mensuales y para su alimentación se les suministraba libra y media de arroz diariamente. Si caían enfermos se les atendía en el hospital descontándoles por cada día de estancia la parte correspondiente de su salario ${ }^{28}$. En el caso de los emancipados cubanos la situación era similar. El artículo 5 del Reglamento para el régimen de los negros emancipados de la colonia aprobado por real orden de 24 de julio de 1864 dice: «En los casos de enfermedad, los emancipados recibirán asistencia facultativa, a cuyos gastos se atenderá con el real diario que el enfermo recibiría en mano si no lo estuviese, sin perjuicio de abonársele el resto del salario en su libreta. Este abono cesará cuando la enfermedad proceda de malicia, en cuyo caso se le descontarán, además del que ya tuviese, tantos reales como días haya dejado el individuo de asistir al trabajo que le está asignado, sin perjuicio del castigo a que se haya hecho acreedor».

Existen, no obstante, ejemplos, en situaciones de emergencia, en que los facultativos del hospital militar prestaron servicios gratuitos a la población de Santa Isabel. Durante la epidemia de viruela, el día 10 de junio de 1864, se publicó un edicto haciendo ver a los habitantes de Santa Isabel que los médicos militares españoles prestarían asistencia gratuita a los atacados de viruela con la única condición de que los enfermos se sujetasen estrictamente a las prescripciones facultativas. Para hacer efectiva esta asistencia Santa Isabel fue dividida en dos distritos y en total fueron atendidos 380 individuos.

A la vista de estos datos parece concluirse que la actividad de la sección del cuerpo de Sanidad Militar estuvo reducida a un grupo pequeño de la población de Santa Isabel. Esto no es así. Exceptuando a los bubis, que no residían en la capital y que utilizaban sus propias terapias herborísticas y religiosas (amuletos y oraciones), la población de Santa Isabel era bastante reducida. El censo de población de 1858 , ya mencionado, recogía una población total de 858 personas. El censo de 1864, reseñado por el médico mayor Melitino López y en el que se incluía a los españoles, daba una población total de 1396 personas divididas de la siguiente manera: blancos (148 varones y 1 hembra), negros (923 varones y 317 hembras) y mulatos (5 varones y 2 hembras). Si tenemos en cuenta que los blancos eran 149, y que de los sectores necesarios para el mantenimiento de los intereses coloniales los krumanes sumaban 439 personas y los emancipados cubanos 194, es decir, entre los tres un $56 \%$ del total, podemos deducir que el esfuerzo médico desarrollado por el escaso personal de Sanidad Militar fue muy importante.

La actividad de los médicos militares españoles no se limitó a una labor clínica y asistencial sino que las experiencias diarias y

\footnotetext{
${ }^{28}$ CASTRO ANTOLÍN, Mariano L.: op.cit. nota 5, p. 27.
} 
la observación del entorno llevó a alguno de ellos, más inquietos, a la publicación de trabajos científicos y de investigación en las revistas nacionales de sanidad militar.

El primer ayudante farmacéutico Ignacio Vives, que con el paso del tiempo llegaría a ser Inspector Farmacéutico de $2^{\text {a }}$ clase y director del Laboratorio Central y Depósito de medicinas, publicó en la Revista General de ciencias médicas y de Sanidad Militar $^{29}$ un extenso trabajo fruto de cuatro años de permanencia y estudios sobre los vegetales observados en Fernando Poo, clasificándolos por familias según el método natural de Decandolle. Se trata de uno de los primeros estudios, si no del primero, que intenta dar a conocer parte de la inmensa riqueza botánica de Fernando Poo, dando noticia, sobre cada planta, de su situación geográfica y de su utilización por los habitantes de Fernando Poo.

Ignacio Vives prestó atención también a la potabilidad de las aguas de Santa Isabel ${ }^{30}$, analizando las aguas de la fuente del Gobernador y las del río Cónsul. La fuente del Gobernador estaba situada al nordeste de la ciudad, a 400 pasos de la antigua calle de Jesús y tras numerosos análisis Vives determinó que estas aguas estaban compuestas por ácidos inorgánicos (ácidos carbónico, clorhídrico y fosfórico), bases inorgánicas (potasa, sosa, cal y magnesia) y ácidos orgánicos (ácido crénico y apocrénico), llegando a la conclusión de que eran aguas potables de primera calidad. Similares análisis realizados sobre las aguas del río Cónsul determinaron idénticas sustancias que las de la fuente del Gobernador pero con la adición de ácido nítrico. Según opinión de Vives las aguas del río Cónsul estaban más expuestas a sufrir variaciones en su composición y por ello aconsejaba, para uso humano, las aguas de la fuente del Gobernador.

El médico mayor Melitino López Sánchez-Nieto, que se retiró en 1885 como Inspector Médico de $1^{\text {a }}$ clase y que en su dilatada carrera militar fue Director de la Academia de Sanidad Militar, también utilizó su experiencia profesional en Fernando Poo para la redacción de artículos de carácter científico. Sus vivencias durante la epidemia de viruela le llevó a redactar un largo artícu$10^{31}$ sobre esta enfermedad, que dividió en dos partes: la primera sobre la aparición y evolución de la epidemia en Fernando Poo y las medidas adoptadas para combatirla y la segunda un estudio patológico sobre la viruela y sus formas de transmisión, con indicaciones sobre la meteorología coincidente. Su afición a los fenómenos meteorológicos con observaciones de la climatología de Fernando Poo y la realización de diferentes mediciones de tipo atmosférico, le llevó a la recopilación de distintos datos sobre la isla que posteriormente utilizaría en artículos como en el ya citado sobre la viruela o el que publicó en la Revista General de ciencias médicas y de Sanidad Militar titulado «Climatología médica, aclimatación humana» ${ }^{32}$.

\footnotetext{
${ }^{29}$ VIVES NOGUER, Ignacio: «Apuntes sobre la flora general de la isla de Fernando Poo» en Revista General de ciencias médicas y de Sanidad Militar, 88, 89, 90, 91 92, 93, y 94, 1867.

${ }^{30}$ VIVES NOGUER, Ignacio: «Ensayo de análisis de las aguas potables de Santa Isabel en Fernando Poo» en Revista de Sanidad Militar y general de ciencias médicas, 49, 50 y 54, 1866.

${ }^{31}$ Ver nota 21.

${ }^{32}$ LÓPEZ SÁNCHEZ-NIETO, Melitino: «Climatología médica, aclimatación humana» en Revista General de ciencias médicas y Sanidad Militar, 76, 77, $78,79,81,83,84,85,86,87,88,89,90,91$ y 92,1867
}

\section{CONCLUSIONES}

El cambio en España hacia un sistema liberal y, fundamentalmente, la necesidad de una reducción presupuestaria determinó que el modelo colonizador propuesto por el estatuto de 1858 fuese abandonado. La iniciativa colonizadora se dejaba en manos privadas limitándose el Estado, únicamente, a mantener la soberanía en la zona.

La retirada del Ejército de Guinea obedeció a este cambio y no fue debida, en ningún caso, al fracaso de su actuación. La actividad desarrollada por los militares en la década estudiada fue enorme: se creó una fuerza de guarnición que colaboró en el desarrollo de las obras públicas, se implantó un modelo de recluta indígena seguido posteriormente por la Infantería de Marina y por la Guardia Colonial, los oficiales de Ingenieros y de Artillería planearon y dirigieron la construcción de edificios, la desecación de pantanos, la creación de caminos, la realización de desmontes, etc. El cuerpo de Sanidad Militar no fue ajeno a este esfuerzo. Con anterioridad a la llegada de la expedición de Carlos Chacón y a la construcción del hospital la actividad sanitaria en Fernando Poo era inexistente. En los diez años de gobierno de los Brigadieres se puso en funcionamiento el hospital, la botica militar, la casa de aclimatación de Santa Cecilia y su enfermería, se dio asistencia hospitalaria a los miembros del Ejército, de la Armada, de la administración colonial y a amplios sectores de la población de Santa Isabel, se hizo frente a tres graves epidemias y todo ello con escasez de medios materiales y humanos y en un entorno hostil para los europeos ${ }^{33}$. En definitiva, diez años de una labor honrada y profesional, germen de lo que muchos años después sería el Servicio de Sanidad de la Guinea española, uno de los mejores de África.

\section{BIBLIOGRAFÍA}

BALMASEDA, Francisco Javier: Los confinados a Fernando Poo e impresiones de un viage a Guinea. Imprenta de la revolución, Nueva York, 1869.

CASTRO ANTOLÍN, Mariano L. de: «La revolución de 1868 y la Guinea española» en Cuadernos de Historia Contemporánea, número extraordinario, 2003.

CASTRO ANTOLÍN, Mariano L. de: La población de Santa Isabel en la segunda mitad del siglo XIX. Asociación Española de Africanistas A.E.A., cuaderno monográfico 1, Madrid, 1996.

CASTRO, Mariano y NDONGO, Donato: España en Guinea. Construcción del desencuentro: 1778-1968. Ediciones Sequitur, 1998.

Diarios y periódicos de la época

GRANDA ORIVE, Javier de: «Aproximación histórica a la compañía de infantería de Fernando Poo» en Ejército, 825, diciembre 2009.

IGLESIAS Y PARDO, Luis: Observaciones teórico-prácticas sobre las fiebres africanas de Fernando Poo. Imprenta y Lit. de Taxonera, Ferrol, 1874.

LÓPEZ SÁNCHEZ-NIETO, Melitino: «Climatología médica, aclimatación humana» en Revista General de ciencias médicas y Sanidad Militar, 76, 77, 78, 79, 81, 83, 84, 85, 86, 87, 88, 89, 90, 91 y 92, 1867.

LÓPEZ SÁNCHEZ-NIETO, Melitino: «Epidemia de viruelas sufrida en Fernando Poo en 1864» en Revista de Sanidad Militar Española y Extranjera 39, 40, 41, 42, 43, 45, 46, y 48, 1865 y en Revista de Sanidad Militar y general de ciencias médicas, 52 y 54, 1866.

MEDINA DOMENECH, Rosa María: «Paludismo, explotación y racismo en Guinea Ecuatorial (1900-1939)» en http://www.asodegue.org/hcp0039.htm MUÑOZ GAVIRIA, Vizconde de San Javier: Tres años en Fernando Poo. Viaje a África. Urbano Manini, Editor, Madrid, 1871.

${ }^{33}$ En Fernando Poo murieron el primer ayudante médico Marcelino Pérez Llanos y el practicante Lorenzo Bronchal. 


\section{J. De Granda Orive}

- NAVARRO, Joaquín J.: Apuntes sobre el estado de la costa occidental de África y principalmente de las posesiones españolas en el golfo de Guinea. Imprenta Nacional, Madrid, 1859.

- VILLAR, José de: «Informe médico acerca del establecimiento de Santa Cecilia en Fernando Poo» en Revista de Sanidad Militar y general de ciencias médicas, 62 y $63,1866$.
- VIVES NOGUER, Ignacio: «Apuntes sobre la flora general de la isla de Fernando Poo» en Revista General de ciencias médicas y de Sanidad Militar, 88, 89, 90, 91 92, 93, y 94, 1867.

VIVES NOGUER, Ignacio: «Ensayo de análisis de las aguas potables de Santa Isabel en Fernando Poo» en Revista de Sanidad Militar y general de ciencias médicas, 49, 50 y 54, 1866 